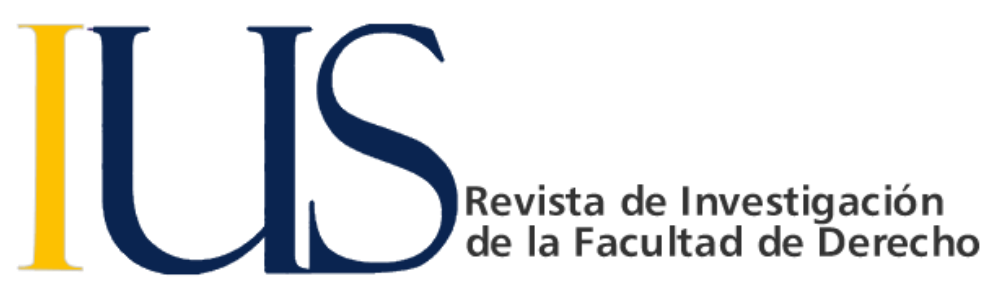

\title{
EL PRINCIPIO DE MÍNIMA INTERVENCIÓN DEL DERECHO PENAL FRENTE A LOS DELITOS DE VIOLACIÓN SEXUAL DE MENOR DE EDAD
}

\author{
CÉSAR GOICOCHEA JIMÉNEZ ${ }^{1}$ CAROLINA CÓRDOVA YAURI ${ }^{2}$
}

\begin{tabular}{ll}
\hline INFORMACIÓN DEL ARTÍCULO & RESUMEN \\
\hline Historia del artículo: & LOs autores desarrollan las implicancias del Principio de Mínima Intervención \\
Recibido el 21 de junio de 2019 & del Derecho Penal vinculado al ámbito punitivo en el delito de Violación Sexual \\
Aceptado el 05 de setiembre de 2019 & de Menor de Edad, con la finalidad de que cada análisis que se realice pueda \\
& contribuir a una mejor resolución de los diversos casos de indemnidad sexual \\
\hline Palabras clave: & de menor de edad, siempre y cuando cumpla con las características que se \\
Derecho Penal. & señalan en la presente investigación. \\
Principio de Lesividad. &
\end{tabular}

Principio de Mínima Intervención

Violación sexual

\begin{abstract}
The principle of minimum intervention of criminal law against crimes of sexual violation of lower age

\section{ABSTRACT}

The authors develop the implications of the Principle of Minimum Intervention of Criminal Law linked to the punitive scope in the crime of Sexual Violation of Minors, with the purpose that each analysis carried out may contribute to a better resolution of the various cases of sexual indemnity of minor, as long as it complies with the characteristics indicated in the present investigation.
\end{abstract}

\section{Keywords:}

Criminal law.

Principle of Lesivity.

Principle of Minimum Intervention.

Sexual violation

\section{Introducción}

Una de las principales funciones que debe realizar todo gobernante dentro de una sociedad, es establecer ciertas reglas para coadyuvar a la convivencia pacífica, estas pueden ser en cierta medida más gravosas que otras, debido a la naturaleza propia de los actos que puedan atentar contra ciertos intereses de la colectividad y que resulten fundamentales para la misma. Desde el ámbito de control más gravoso se encuentra en el último de los peldaños, pero no por la importancia, sino por su implicancia, al derecho penal.
Este tipo de control se ha precisado a lo largo del tiempo es parte del denominado control social.

Sin embargo, es importante precisar que no se trata de un control o de un ejercicio del poder de manera arbitraria y desmesurada, sino que para que el mismo pueda ser en cierta medida, garantista, requiere de ciertos límites o controles. Estos límites se encuentran relacionados con la función que deben realizar los gobernadores para que así el establecer una conducta contraria y que sea considerada delito, no sea por la simple voluntad de quiénes se encargan de promulgar

\footnotetext{
${ }^{1}$ Asistente en Función Fiscal de la Segunda Fiscalía Provincial Penal Corporativa de Sechura. Maestrante en la Maestría en Derecho con Mención en Derecho Penal y Procesal Penal. Piura, Perú. Contacto: cgoicochea.wb@gmail.com

${ }^{2}$ Fiscal Provincial del Cuarto Despacho de la Tercera Fiscalía Provincial Penal Corporativa de Piura. Egresada de la Maestría en Derecho con Mención en Derecho Penal. Piura, Perú. Contacto: daniela260608@hotmail.com
} 
las leyes, sino que justamente protejan los intereses colectivos, intereses que se traducen en bienes jurídicos tutelados.

Estos límites encuentran su razón de ser en una serie de principios, garantizando que antes de establecer un hecho como delito, se busque que otros mecanismos de control puedan encontrar una solución. Dentro de los principios más resaltantes de la función estatal para la regulación de normas penales, se encuentran el principio de legalidad, lesividad y mínima intervención del derecho penal. Los tres principios, y como se desarrollará en líneas posteriores, buscan que las reglas estén previamente establecidas y se haya delimitado cual es el interés de la colectividad que se está vulnerando, y como se menciona, establecer como último mecanismo la tipificación de un hecho como delito, sin dejar de pensar tampoco, en si la pena a imponer como consecuencia de la comisión de hecho típico, resulta ser razonable y no atenta contra otros intereses que deben sobreponerse a la idea de imponer una sanción penal.

Dentro de la protección a bienes jurídicos que realiza el Estado, se encuentra el vinculado a la indemnidad sexual de menores de edad, con la finalidad de preservar los intereses propios de los menores de 14 años de edad, sin que tenga implicancia en la comisión del hecho, que él o la menor manifiesten aceptación en la realización del acto. Sin embargo, de acuerdo a lo que establece el artículo 15 del Código Penal, pueden surgir ciertos problemas en cuanto a la configuración del delito de violación sexual de menor de edad, debido a las consecuencias jurídicas del mencionado artículo, toda vez que exime de responsabilidad a aquella persona que por su cultura o costumbre comete un hecho punible sin poder comprender el carácter delictuoso de su acto. Adicionalmente, otro de los problemas que puede surgir es cuando se sostiene relaciones sexuales con un o una menor de catorce años, en una edad cercana a ella, y producto de la misma se genera una relación de convivencia.

Ante estos dos problemas que se pueden generar, surgen las siguientes interrogantes ¿Cuál debería el límite punitivo por parte del Estado al momento de imponer sanciones penales a una persona que mantiene relaciones sexuales con una menor de edad, pero que producto de la misma se genera una relación de convivencia? O, ¿̇El hecho de mantener relaciones sexuales con un o una menor de catorce años, bajo la condición de error de comprensión culturalmente condicionado, conlleva a que se exima de responsabilidad penal?
Ambas interrogantes serán desarrolladas en la presente investigación, lo que se traduce en que el principal objetivo es establecer cuáles deberían ser las consideraciones para la imposición de una condena en una persona que mantiene relaciones sexuales con un o una menor de edad y de la que se puede generar una relación de convivencia y de dependencia. Asimismo, poder establecer los límites a la aplicación del error de comprensión culturalmente condicionado como eximente de responsabilidad penal. Además de los objetivos planteados y que serán desarrollados, también se realizará una breve explicación acerca del poder punitivo del Estado y los principales principios que son tomados como límites a su actuación.

Finalmente, como hipótesis de la investigación se establece que sí es posible establecer una reducción y un eximente de la responsabilidad penal, siempre y cuando concurran una serie de presupuestos legales en cada caso particular para que pueda establecerse de dicha manera. Esta hipótesis se sustenta en las distintas Resoluciones de la Corte Suprema y en el Acuerdo Plenario referente al error de comprensión culturalmente condicionado.

\section{EL PODER PUNITIVO DEL ESTADO Y PRINCIPALES PRINCIPIOS LIMITATIVOS}

\subsection{El poder punitivo del Estado}

Antes de iniciar con el desarrollo referente al tema central del presente estudio, consideramos que es importante entender el porqué del surgimiento de los principios penales y específicamente, del principio de mínima intervención del Derecho. Con esto no pretendemos tampoco tener como principal objetivo el desarrollar el contexto histórico de los principios, sino que únicamente se desarrolle lo relativo al poder punitivo estatal y en base a ello establecer los límites que guardan relación con la atribución antes mencionada.

El poder punitivo del Estado o también llamado "Ius Puniendi" del Estado, es entendido como aquella facultad de todo Estado capaz de castigar mediante actos propios de carácter penal (reglas penales), y que las mismas resultan necesarias para salvaguardar el orden dentro de una determinada sociedad (Creus Monti, 2009, p. 5). Como resulta evidente, esta atribución "puniendi" que todo Estado posee, surge como una necesidad de orden público, entiéndase 
como una medida de "control social" ${ }^{3}$ y que resulta necesaria, para que así se puedan considerar a ciertas conductas como prohibidas, y por ende, que las mismas sean castigadas de manera ejemplar, aunque en la actualidad esta función se haya desnaturalizado para convertirse en algunos casos en mecanismos de satisfacción a los requerimientos de los ciudadanos, conllevando a que no se cumplan o no se establezcan políticas integrales que conlleven a buscar las soluciones a diversos problemas que aquejan a la sociedad.

Si trasladamos a nivel de los principios, se debe reconocer que el ius puniendi se encuentra en relación a la protección de bienes jurídicos protegidos ${ }^{4}$ (principio de lesividad ${ }^{5}$ ), lo que ha sido detallado por el derecho penal moderno. En razón a ello, el legislador realiza sus acciones mediante la amenaza con imposición de penas a las acciones que vulneran (o ponen en peligro) determinados intereses de una sociedad (Bacigalupo Zapater, 2004, p. 42). Lo anteriormente señalado no es más que la manifestación propia del ius puniendi, el mismo que se encuentra sustentado en la potestad de un determinado Estado en castigar conductas que consideren contrarias al orden público y a los intereses de la colectividad, estableciendo así un marco normativo de carácter punitivo para aquellas conductas que resulten ser contrarias.

\subsection{Límites al poder punitivo del Estado}

Por ser el ius puniendi del Estado una de las manifestaciones del Poder que ostenta ${ }^{6}$, existen diversos límites de control que deben efectuarse para poder evitar el abuso que puedan cometer aquellos funcionarios o gobernantes encargados de emitir las normas. En esa misma línea Reátegui Sánchez (2009) sostiene que "solo aquel Derecho Penal (ordenamiento jurídico) que se ajuste a los cánones constitucionales,

\footnotetext{
${ }^{3}$ De igual manera, JESCHECK (1981) hace referencia a que "el sustento de los límites de la función punitiva del Estado Social y Democrático de Derecho se basa en un núcleo de derecho que según la conciencia jurídica general no puede ser vulnerado por ninguna ley, ni por ninguna otra medida emanada del poder público; es un núcleo inviolable y que está sustraído al ejercicio del poder estatal para proteger la dignidad humana".

4 En ese mismo sentido también se encuentra lo sostenido por HUARCAYA RAMOS $(2017,0.302)$, quien sostiene que No hay imposición de pena sin lesión o puesta en peligro de un bien jurídico tutelado por la ley penal.

5 Entiéndase que el artículo IV del Título Preliminar del C.P. regula que la pena necesariamente precisa de la lesión o puesta en peligro de bienes jurídicos tutelados por la ley. Si bien es cierto, la protección va en relación al bien jurídico
}

será considerado como un sistema normativo garantista y limitante del poder estatal. No solo hay que observar los aspectos principistas del carácter sustantivo (principio de legalidad, protección exclusiva de bienes jurídicos, entre otros), sino también límites formales o garantías de derecho procesal como la garantía jurisdiccional, debido proceso, juez imparcial, entre otros. $Y$ es que más que un conjunto de normas que puedan determinar lo que es correcto o no, el límite al poder punitivo del Estado encuentra su sustento en la protección y garantía de los derechos fundamentales de las personas que se encuentran regulados en las diversas normas de nuestro ordenamiento interno y externo".

Un segundo jurista, García Cavero (2012) sostiene que "la justificación de los principios político-criminales puede encontrarse tanto en una perspectiva preventiva como en una re estabilizadora del Derecho Penal. En la lógica preventiva, la pena no solamente debe ser eficaz para prevenir delitos, sino que debe también orientarse al respeto de las garantías jurídico-penales; mientras que para otros, la prevención de los delitos requiere de una pena justa, es decir, que se corresponda con los criterios de justicia, proporcionalidad, etc." (pp. 117118) Efectivamente, el ejercicio del ius puniendi del Estado no puede considerarse como una actividad sin límites, sino que, como se mencionó anteriormente, encuentra sus limitaciones dentro del ámbito constitucional. Para citar un ejemplo, un límite al poder punitivo del Estado es el llamado principio de legalidad, el cual implica que ningún acto podrá ser considerado como ilícito si al momento de su comisión no se encontraba regulado como tal. Los límites básicos del ius puniendi quedan plasmados en la propia Constitución, razón por la cual suelen ser denominados, con mayor o menor propiedad, principios constitucionales del derecho pena (Polaino Navarrete,

protegido, también es cierto que el C. P. P. de 2004 haga referencia a que no necesariamente el titular del bien jurídico protegido será aquel sujeto que pueda accionar o solicitar una medida contra la acción que ha causado algún daño o posible daño, sino que, se considera a todo aquel sujeto ofendido o perjudicado dentro de la acción delictiva (artículo 91 inciso 1 del CPP). No se pretende realizar un mayor ahondamiento en la presente explicación, porque será materia de desarrollo en la presente investigación.

6 Estado es único e indivisible, por lo que cuando se menciona Poder del Estado, solo se está haciendo referencia a una terminación tradicional, muy por el contrario a ello, no estamos frente a una división de poderes porque finalmente, lo que se puede dividir son las funciones que son atribuidas de manera exclusiva a ciertas Instituciones del Estado. 
2008, p. 168). Dicho ello, queda evidenciado que el límite principal al accionar tiene que basarse en lo regulado en nuestra Constitución Política. Si una norma es arbitraria, carece de sentido o es interpretada de manera errónea por algún administrador de justicia (juez), existe la posibilidad que se realice un control constitucional contra las arbitrariedades cometidas.

El Tribunal Constitucional en reiterada jurisprudencia ha establecido cuáles son las limitaciones al ius puniendi del Estado y que justamente se condice con lo manifestado anteriormente. Así, el ius puniendi funciona con sus limitaciones dentro de un marco penal de la Constitución, bajo los estándares internacionales referidos a la protección de derechos fundamentales y en estricta observancia de los fines de la pena. En este sentido, nuestro ordenamiento Constitucional y las obligaciones internacionales serán el punto de inicio para poder establecer los fines que el régimen penitenciario se ha propuesto lograr y los objetivos que en ella se ha trazado en la Constitución, así como cumplir con los deberes y obligaciones asumidas por el Estado ${ }^{7}$.

De igual manera, si lo queremos trasladar al proceso penal, la doble instancia dentro del proceso encontraría su sustento, porque si un juez realiza una mal interpretación o adecuación de la norma, el Superior deberá corregir y enmendar dicha vulneración con la finalidad de salvaguardar el interés que realmente deben ser tutelados.

Sin realizar mayor desarrollo respecto a los principios que forman parte del límite del ius puniendi del Estado, es importante conceptualizar a los mismos, para que a partir de los mismos se realice el análisis central de la investigación, referida a la vinculación del principio de mínima intervención del derecho penal frente a los delitos de violación sexual.

\section{a) Principio de legalidad.}

Quizás la importancia de este principio no radica únicamente dentro del Sistema Penal, sino que su importancia tiene implicancia en todos los procesos, y en general, en todo el sistema jurídico de nuestro país y porque además hacen posible la existencia del mismo. Manifestamos esto, porque además de ser un principio, también significa un límite al poder de los gobernantes,

7 Sentencia del Tribunal Constitucional Exp. 0033-2007$\mathrm{PI} / \mathrm{TC}$, fundamento 26 .

8 De igual forma el Artículo II del Título Preliminar del C. P. establece que nadie será sancionado por un acto no previsto como delito o falta por la ley vigente al momento de su porque si no existe una norma es imposible que se pueda actuar.

La Constitución regula al principio de legalidad dentro del artículo 2, inciso 20 numeral d, en el que se establece constitucionalmente que nadie será procesado ni condenado por acto y omisión que al tiempo de cometerse no está previamente calificado en la ley, de manera expresa e inequívoca, como infracción punible, ni sancionado con pena no prevista en la Ley ${ }^{8}$. Resulta necesaria hacer esta precisión, ya que este principio, al ser el pilar fundamental de todo el ordenamiento jurídico, va a regular aquellas conductas que son consideradas como delitos y además, va a regular la forma en cómo se debe llevar un proceso penal, con las garantías ya establecidas.

Así, el TC en el Exp. 0016-2002-Al/TC ${ }^{9}$ ha establecido que el principio de legalidad es equiparable a la seguridad jurídica, porque es un principio que transita todo el ordenamiento jurídico. El reconocimiento del mismo se encuentra implícito dentro de nuestra Constitución, aunque se concretiza con meridiana claridad en las distintas disposiciones constitucionales. De igual manera, en el Exp. 0010-2002-Al/TC ${ }^{10}$ ha determinado que el principio de legalidad exige no solo que por ley se establezcan los delitos, sino también que las conductas prohibidas estén delimitadas en la ley. Resulta evidente lo que se ha venido sosteniendo en líneas anteriores, al considerar al principio de legalidad como principio rector de todo nuestro ordenamiento jurídico, sin él, el Estado y sus Poderes no tendrían razón alguna.

De acuerdo a lo sostenido por Mir Puig (Montes Flores, Peña Cabrera, pp. 66-67), el principio de legalidad, en su aspecto formal, se expresa con el aforismo nullum crimen, nulla poena sine lege, el mismo que hace referencia a que no puede haber crimen ni pena si es que no hay una ley que determine el hecho como ilícito. Entiéndase entonces que no solo se puede concebir como un mecanismo de seguridad jurídica, sino que más allá de que un ciudadano no pueda ser juzgado si es que no existe una norma que determine un hecho como tal, implica la necesidad razonable de que tal hecho pueda ser considerado como tal.

En suma, lo imporante de este principio, es establecer las garantías claras para las personas dentro de un determinado territorio, estableciéndose o

comisión, ni sometido a pena o medida de seguridad que no se encuentren establecidas en ella.

9 Cfr. Sentencia del Tribunal Constitucional Exp. 00162002-Al/TC, fundamento 4.

10 Sentencia del Tribunal Constitucional Exp. 0010-2002$\mathrm{Al} / \mathrm{TC}$, fundamento 45 . 
conceptualizando a las conductas que deben ser consideradas como delitos, sin que una conducta pueda ser considerada como tal hasta que en la norma penal no se haya establecido de manera taxativa.

\section{b) Principio de lesividad ${ }^{11}$.}

Resulta importante analizar el presente principio como límite al ius puniendi del Estado porque es justamente, en primer término, el que nos va a dar una apreciación acerca de lo que protege el sistema y el Derecho Penal. Como se mencionó anteriormente, el artículo IV del Título Preliminar del Código Penal da una idea primigenia que implica la protección de los bienes jurídicos ante la lesión o amenaza de lesión. De acuerdo a esa idea, "no hay hecho punible sin bien jurídico vulnerado o puesto en peligro" (De La Mata Amaya, Sánchez Tomás y Alcácer Guirao, 2007). Entonces, para que una conducta sea señalada como delito, se requiere en primer lugar, hacer un análisis de qué tipo de bien jurídico podríamos estar lesionando con esa conducta, posteriormente a ello ya vendría la tipificación penal. Recordemos así que el derecho penal es un sistema, dentro del ámbito normativo, de última ratio, lo que implica que si se pueden solucionar los problemas con las otras ramas del derecho, no tendría razón de hacer la aplicación de este sistema, más aún, si las consecuencias son más gravosas que los demás. Este principio constituye un límite al poder punitivo estatal por cuanto el Estado no puede establecer hechos punibles en virtud de la existencia de un bien jurídico digno de protección (De La Mata Amaya, Sánchez Tomás y Alcácer Guirao, 2007).

La intervención punitiva solo es viable en relación a conductas que tengan trascendencia social y que afecten las esferas de libertad ajenas, sin que le sea permitido al derecho penal castigar comportamientos contrarios a la ética, inmorales o antiestéticos, so pena de invadir los terrenos de la moral (Velásquez Velásquez, s.f.). Dicho ello, no cabe la posibilidad de que se puedan castigar cualquier tipo de conductas, como se ha mencionado líneas atrás, porque el derecho penal

11 Entendemos que el principio de lesividad hace mención -según la postura de cada autor- también al principio de exclusiva protección de bienes jurídicos. Ello en base a que finalmente es el bien jurídico lo que sirve como fundamento y como fin del derecho penal. Aunque también podríamos entender-de acuerdo a lo que se explica más adelante- que el bien jurídico no se encuentra de manera exclusiva relacionado con el derecho penal, porque finalmente la protección de los mismos sostienen todo el ordenamiento jurídico, sea peruano o de otro país. Por citar algunos ejemplos, (Quintero Olivares, 2007, p. 79) cuando se refiere al principio de exclusiva protección de bienes jurídicos, no únicamente podrá encargarse de regular y de castigar aquellos hechos que realmente generen un impacto negativo a la sociedad, pero tampoco se trata de cualquier impacto, sino que transgreda de manera directa bienes jurídicos que se encuentran con titularidad o posesión, con ello para asegurar una buena convivencia, para cumplir lo que se ha estipulado dentro del Ilamado control social que se debe establecer en toda sociedad.

Como afirma García Rivas (1996, p. 47), “si bien en la mayor parte de los casos las normas penales sirven para la tutela de bienes jurídicos, ello no excluye que puedan conminarse penalmente determinadas formas de comportamiento especialmente reprobables desde el punto de vista ético, execrables para el común sentir, incluso si de su realización no se deriva inmediatamente la lesión de un bien jurídico". Esta fundamentación realizada nos da una primera aproximación al sustento de la presente investigación, por cuanto se determina que no necesariamente podemos hacer referencia a la lesión de un bien jurídico como protección del derecho penal, sino que, existen delitos pluriofensivos y que recaen no solamente en el sujeto pasivo del delito (titular del bien jurídico), sino que también en aquel sujeto pasivo de la acción (persona distinta al titular del bien jurídico sobre quien recae la acción delictiva).

\section{c) Principio de mínima intervención.}

Una primera apreciación respecto al principio de mínima intervención, radicaría en que el Derecho Penal solamente intervendrá en aquellos supuestos que son permitidos por el principio de lesividad, entiéndase que podrá ser efectivo por lo ya mencionado anteriormente, cuando los demás sectores del ordenamiento jurídico fracasan, por ello es que se considera al derecho penal de última ratio, aunque en la actualidad sea visto como el único sistema capaz de solucionar todos los problemas que ocurran en nuestra sociedad. Dicho ello, la pena es última ratio de la política social, y el derecho penal solo protege parte de los bienes jurídicos.

hace mayor referencia a que la ley penal prohíbe una seria de acciones, cuya realización u omisión ponen en peligro o lesionan un interés espiritual o material generalmente apreciado. De igual manera (Villavicencio Terreros, 2006, pp.94-95) también se refiere al principio de exclusiva protección asemejándolo con el de lesividad u ofensividad, haciendo mención al artículo IV del C. P. No merece mayor ahondamiento en la investigación porque queda claro que si bien hay una diferenciación respecto a la denominación, lo cierto es que en la fundamentación no se precisa mayor distinción, inclusive, señalándose el uno con el otro. 
Para tener una mejor comprensión, Castillo Alva (2004, p. 210) sostiene que si el derecho penal es la rama del ordenamiento jurídico que alberga las sanciones más graves, debe entenderse que su empleo no puede ser indiscriminado, permanente y sin ningún límite. $Y$ es justamente lo que se ha venido sosteniendo hasta este momento, entendemos que no requiere mayor profundidad el análisis de este principio, ya que la fundamentación del mismo se basa en el derecho penal como última ratio y como necesidad, no como prioridad cuando existen otros mecanismos para poder hacer frente a diversos actos (Bramont-Arias, 2000, pp. 66$67)^{12}$.

Este principio, conforme a lo sostenido por Huarcaya Ramos (2017, p. 314), tiene su fundamento en que las consecuencias y repercusiones del hecho deben necesariamente ser socialmente relevantes y se proyecten en la sociedad. La violencia punitiva del Estado no puede sobrepasar el límite de la dignidad de la persona y la perspectiva de promover siempre una lógica a favor de la libertad y no a favor de la represión. Adicionalmente, Villavicencio Terreros (2006, pp. 9293) sostiene que "el derecho penal se legitima solo cuando protege a la sociedad, pero si su intervención resulta inútil, entonces perderá su justificación. (...) Por eso, este principio conduce a la exigencia de utilidad. La mera utilización de instrumentos violentos como la pena siempre afectará la idea de un Estado de derecho. Por eso, para que intervenga el derecho penal, su presencia debe ser absolutamente imprescindible y necesaria, ya que de lo contrario generaría una lesión inútil de los derechos fundamentales". Esta idea es lo que se ha venido sosteniendo en los párrafos precedentes, por cuanto únicamente se debe activar el poder punitivo del Estado a través de la aplicación de las

12 El principio de intervención mínima tiene en cuenta lo siguiente: a) Principio de Fragmentariedad, que se basa en que el derecho penal no protege todos los bienes jurídicos, sino sólo los más importantes; b) Principio de subsidiariedad, por el mismo hecho de ser última ratio, deberá demostrarse que la acción realizada que causó algún daño no es reemplazable por otros métodos de control social; c) Principio de proporcionalidad, que encuentra su sustento en la imposición de pena como idónea o proporcional a la magnitud del daño causado y al desprecio al orden jurídico. De igual manera el TC en la sentencia recaída en la Sentencia del Expediente 17-2011/Al, fundamento 10, ha fundamentado que no se trata tampoco de que la sola existencia de un bien jurídico a ser protegido genere per se la necesidad de recurrir a la sanción penal para protegerla. Ello, porque justamente de lo que se trata es de hacer efectivos los demás sistemas del ordenamiento jurídico que existen, sino ninguno tendría razón de ser. De igual manera la Sala Penal Permanente de la Corte Suprema en la normas penales, cuando las circunstancias del caso así lo ameriten, sin que esta signifique un exceso. Además, porque únicamente puede activarse el sistema persecutorio penal cuando el daño al bien jurídico o a los intereses del Estado resulten dañados de manera significativa, caso contrario, habría que establecer una sanción sin que la misma signifique un exceso penal.

Finalmente, es importante acotar que el principio de mínima intervención del derecho penal no solamente se encuentra vinculado a la protección de bienes jurídicos frente a ataques gravemente reprochables, sino que es posible afirmar que este principio también repercute en los elementos propios que forman parte de los requisitos de la pena. "Ello significa que la imposición de una pena privativa de libertad debe imponerse solamente cuando las acciones imputadas sean punibles, pese a que las mismas sean típicas, antijurídicas y culpables. En otras palabras, la pena concurrirá cuando esta sea merecida, proporcionada y necesaria" Luzón Peña (Núñez Chasquero, 2016) ${ }^{13}$.

En ese sentido no deben quedar dudas que el principio de mínima intervención del derecho penal cumple dos funciones propiamente, la primera la de establecer mediante un análisis objetivo, si una conducta específica puede ser considerada como delito y no existen otros mecanismos menos gravosos para poder acudir a realizar alguna pretensión en particular; en segundo lugar porque aun y cuando la conducta pueda cumplir con los elementos típicos de la teoría del delito, debe verificarse si la pena a imponer es necesaria y proporcional al hecho en específico, haciendo un análisis de diversas circunstancias que pudieran encontrarse en el sujeto y/o en el hecho en concreto.

Resolución de Nulidad del 19 de marzo de 2010 del expediente 238-2009, fundamento 5, ha fundamentado que el principio de intervención mínima del Derecho penal está integrado por el carácter fragmentario de este último y por el principio de subsidiariedad, y consiste en que la intervención del Estado sólo se justifica cuando es necesaria para el mantenimiento de su organización, por ello, sólo debe acudirse al derecho penal cuando han fracasado todos los demás controles, pues el derecho punitivo es el último recurso ya que no castiga todas las conductas lesivas de bienes jurídicas, sino sólo las que revisten mayor gravedad. 13 Adicionalmente, es importante precisar que de acuerdo a ROXIN (Derecho Penal Parte General, p. 984), una pena privativa de libertad es merecida cuando una conducta es catalogada como típica, antijurídica y culpable, únicamente; proporcionada, cuando guarda correspondencia con la responsabilidad individual del infractor penal; y, necesaria, cuando mediante ella se pueden concretar los fines generales y especiales. 


\section{EL DELITO DE VIOLACIÓN SEXUAL DE MENOR DE EDAD}

El delito de violación sexual se encuentra tipificado en el artículo 173 del Código Penal, cuya descripción legal es la siguiente: "El que tiene acceso carnal por vía vaginal, anal o bucal o realiza otros actos análogos introduciendo objetos o partes del cuerpo por alguna de las dos primeras vías con un menor de edad, será reprimido con las siguientes penas privativas de libertad: 1) Si la víctima tiene menos de diez años de edad la pena será de cadena perpetua. 2) Si la víctima tiene entre diez años de edad, y menos de catorce, la pena será no menor de treinta, ni mayor de treinta y cinco años. En el caso del numeral 2, la pena será de cadena perpetua si el agente tiene cualquier posición, cargo o vínculo familiar que le dé particular autoridad sobre la víctima o le impulse a depositar en él su confianza".

\section{a) Tipicidad Objetiva}

Conforme lo establece el citado texto legal, para la configuración del tipo penal de violación sexual de menor de edad, es indistinto si él o la menor prestan su consentimiento para realizar el acto sexual. En ese sentido no se encuentra en cuestionamiento tampoco el uso de la violencia o amenaza, por lo anteriormente afirmado. Esto último en concordancia con lo establecido también en el artículo 20 inciso 10 del Código Penal, el mismo que establece que está exento de responsabilidad penal aquella persona que actúa con el consentimiento válido del titular de un bien jurídico protegido de libre disposición.

En ese sentido el Dr. Villa Stein (Salinas Siccha, 2016), sostiene que la concurrencia adicional de violencia o intimidación es indiferente aunque debe servir al juzgador para graduar la pena entre los polos máximos y mínimos, como debe servirle, para el mismo propósito, el consentimiento psicológico de la víctima. Corresponde entonces establecer que no se requiere el acto de violencia contra el menor o la menor de catorce años de edad, toda vez que la ausencia de manifestación de voluntad para la realización de dicho acto, conlleva a que el acto sexual que se cometa sea ilícito, por cuanto y como se ha sostenido, el menor no cuenta con la capacidad plena para disponer de su libertad sexual.

Finalmente y como explicación del criterio que establece la Corte Suprema en relación a la voluntariedad del menor o la menor de catorce años de edad, a través del Recurso de Nulidad N²239-2013Callao se ha establecido lo siguiente: "La violencia o la amenaza no son elementos descriptivos del tipo penal de violación de menor de edad, por cuanto este tipo penal no tiene como bien jurídico la libertad sexual sino la indemnidad sexual, criminalizando el mero contacto sexual entre el sujeto pasivo y el sujeto activo. Toda vez que la víctima al momento de los hechos tenía menos de diez años, no cabe duda que el mero contacto sexual con la víctima torna típica la conducta del proceso, no siendo necesario emplear como medios para la comisión ni la violencia ni la amenaza".

\section{b) Bien Jurídico Protegido}

Aún y cuando se ha precisado anteriormente lo dispuesto por la Corte Suprema respecto al Bien Jurídico Protegido, es importante precisar que el mismo en el delito de violación sexual de menor de edad es la indemnidad sexual, debiendo entenderse a esta "(...) como la protección del desarrollo normal de la sexual de los menores, quienes todavía no han alcanzado el grado de madurez suficiente para determinarse sexualmente en forma libre y espontánea". (Salinas Siccha, 2016, p. 209).

De igual forma, Peña Cabrera (2015) sostiene que respecto al bien jurídico protegido, "en principio se trata del normal desarrollo de la sexualidad, en cuanto a esfera que se puede ver gravemente comprometida, como consecuencia de relaciones sexuales prematuras; mientras la edad de la víctima vaya en descenso, los efectos perjudiciales serán mayores, de ahí que las penalidades serán mayores". Finalmente no genera dudas conceptualizar al bien jurídico protegido como la indemnidad sexual del menor de edad, del cual se pueden generar diversas repercusiones que van en contra de los mismos.

\section{c) Sujeto Activo}

En cuanto a sujeto activo, lo puede ser tanto varón como mujer, en ambos casos y como se ha mencionado existe un abuso aun y cuando el menor manifieste aceptación, por cuanto como se ha sostenido, la voluntariedad del mismo no tiene mayor relevancia.

\section{d) Sujeto Pasivo}

Sin requerir mayor fundamentación, es considerado sujeto pasivo aquella víctima del delito que es menor de catorce años de edad, independiemiente de si es varón o mujer.

\section{e) Tipicidad subjetiva}

Es un tipo penal doloso, lo que significa que requiere la concurrencia entre el conocimiento y la voluntad del sujeto activo.

\section{EL ERROR DE COMPRENSIÓN CULTURALMENTE CONDICIONADO}


Es necesario e importante, realizar una conceptualización en lo que respecto al error de comprensión culturalmente condicionado y que se encuentra regulado en el artículo 15 del Código Penal, para que a partir de ello se puede lograr un mejor entendimiento del análisis principal de la presente investigación.

Como se mencionó, en el artículo 15 del Código Penal, el legislador reguló esta institución jurídico-penal, de la siguiente manera: "El que por su cultura o costumbres comete un hecho punible sin poder comprender el carácter delictuoso de su acto o determinarse de acuerdo a esa comprensión, será eximido de responsabilidad. Cuando por igual razón, esa posibilidad de halla disminuida, se atenuará la pena".

Reátegui Sánchez (2014), entiende que esta figura jurídica "se encuentra dentro de la teoría del error, y se da cuando el infractor se desarrolló en una cultura distinta a la nuestra y ha internalizado desde niño las pautas de conducta de esa cultura, tal como el caso de los miembros de las comunidades indígenas de la Amazonía, por lo tanto este error afecta la culpabilidad". Y ello porque tal y como se encuentra actualmente legislado, únicamente se podrá invocar el error culturalmente condicionado, cuando por razón de las propias costumbres o cultura en la que se desarrolla un determinado grupo social o de personas, realizan actos que pueden ser considerados como delitos, pero dada las características propias de su cultura, no pueden ser punibles. Esto no condiciona a que si una persona ha sido procesado por el mismo hecho, no puede generar un condicionamiento (Reátegui Sánchez, 2014, p. 734). Ello encuentra su fundamentación porque para aquellas personas que desarrollen cierta actividad, y dadas sus costumbres, no se le presenta el injusto penal como un acto prohibitivo, sino que muy por el contrario, sino que lo realizará y seguirá realizando asumiendo que el mismo es lícito, dada la aceptación del grupo social en el que se encuentra.

Esta institución y como se desarrollará en las siguientes líneas, presenta mayor incidencia en los delitos contra la libertad sexual, por cuanto dentro de un ámbito cultural, ciertas familias aceptan que sus menores hijas (por lo general) inicien una relación a temprana edad con personas adultas, con la promesa de que este último asuma obligaciones para con ella y con la prole, sin que esto pues conlleve necesariamente a afirmar que nos encontramos frente a un delito.

No pretendemos realizar un mayor desarrollo jurisprudencial, en cuanto al supuesto de aplicación del error culturalmente condicionado, por cuanto el mismo, y como se ha mencionado en los párrafos precedentes, forma parte del sustento para el desarrollo de la presente investigación.

\section{EL DELITO DE VIOLACIÓN SEXUAL DE MENOR DE EDAD FRENTE AL PRINCIPIO DE MÍNIMA INTERVENCIÓN DEL DERECHO PENAL}

Se ha fundamentado que el principio de mínima intervención del derecho penal no encuentra su vertiente únicamente en considerarse como última ratio del sistema judicial y como mecanismo coercitivo, sino que también encuentra su relación en la aplicación de sanciones de acuerdo a las circunstancias particulares de cada caso en concreto, debiendo entonces analizar si efectivamente a una persona en particular le corresponde una pena tipificada previamente, o si en el caso mismo se presenta algún elemento que pueda conllevar a disminuir la pena misma. En ese sentido corresponde analizar dos presupuestos para poder establecer la aplicación del principio de mínima intervención del derecho penal.

Como primer análisis para establecer una postura en cuanto a la intervención mínima del Derecho Penal en el aspecto punitivo, se encuentra la figura del Error de comprensión culturalmente condicionado, el mismo que se encuentra regulado en el artículo 15 del Código Penal y cuyo tener es el siguiente: "El que por su cultura o costumbres comete un hecho punible sin poder comprender el carácter delictuoso de su acto o determinarse de acuerdo a esa comprensión, será eximido de responsabilidad. Cuando por igual razón, esa posibilidad se encuentra disminuida, se atenuará la pena".

Bajo este artículo, "el error de comprensión culturalmente condicionado se presenta cuando el infractor se desarrolló en una cultura distinta a la nuestra y ha internalizado desde niño las pautas de conducta de esa cultura, por lo que en definitiva, este error afecta la culpabilidad"14. Respecto a la teoría del delito, en este supuesto de error se cumplen los elementos del tipo penal tal como la conducta, tipicidad, antijuricidad, pero en el caso de la culpabilidad no se cumple el presupuesto por cuanto de acuerdo las condiciones en el que se ha desarrollado la persona, por sus costumbres o cultura, no logra comprender el carácter delictuoso del acto cometido. Si lo trasladamos al desarrollo del presente artículo, sería el hecho de mantener relaciones sexuales con una

14 Ejecutoria Suprema del 01.07.04 - Recurso de Nulidad $\mathrm{N}^{\circ}$ 1037-2004. 
menor de catorce años, lo que finalmente lo va a eximir de responsabilidad penal.

Sin embargo, a raíz de la aplicación indiscriminada del error culturalmente condicionado, sin que se haga un análisis más detallado del mismo en diversas sentencias, la Corte Suprema tuvo a bien emitir el Acuerdo Plenario Nº1-2015/CIJ-116, en el cual se desarrolló la aplicación judicial del artículo 15 del Código Penal y los procesos interculturales por delitos de violación de niñas y adolescentes. Bajo el contexto en el que se emitió el Acuerdo Plenario, se expuso que el problema radica en que en la actualidad, la judicatura penal nacional registra una recurrencia relevante de procesos por delitos de abuso y violencia sexual en agravio de niñas y adolescentes menores de 14 años, los cuales tienen como autores a integrantes de comunidades campesinas y amazónicas del país. Agregando que existe sometimiento sexual a niñas o adolescentes desde que inician a menstruar, matrimonios arreglados, venta con fines matrimoniales, validación y tolerancia al rapto, legitimación de prácticas sexuales tempranas consentidas.

Asimismo, en el mencionado Acuerdo se hace precisión que el error condicionalmente culturado sí debe ser aplicado en ciertos casos, de acuerdo a las condiciones en las que se desarrolla el hecho en concreto, estableciéndose que para la aplicación del error culturalmente condicionado, deberá practicarse lo siguiente en la investigación:

a) Desarrollo de una aplicación selectiva y restringida del artículo 15 del Código Penal, con la finalidad de que no se proyecte de manera indebida sus efectos sobre autores de delitos de abuso y violencia sexual en agravio de niñas y adolescentes menores de catorce años. Lo anteriormente se fundamenta también la prohibición de aplicación del artículo en mención ante cualquier tipo de violencia o sometimiento, aun y cuando haya aceptación posterior de los familiares o algún tipo de compensación, por cuanto se trata de derechos fundamentales.

b) Construcción técnica e idónea de las pericias antropológicas, siendo obligatoria la misma, debiendo ser practicada por un profesional idóneo y con experiencia acreditada. En la pericia se debe detallar el origen de la costumbre y la validez actual. Asimismo deberá contar con la siguiente estructura: antecedentes para la preparación del peritaje, métodos y técnicas de investigación, además del problema planteado; puntos sobre los que se desarrollará el peritaje; finalmente la conclusión, recomendación. c) Incorporación y valoración de otros medios de prueba, en el que se pueden incluir informes (amicus cuiriae), testimonios complementarios, etc.

d) Inserción en el razonamiento y argumentación de las decisiones judiciales de la doctrina nacional e internacional sobre enfoque de género, interés superior del niño y compensación de la vulnerabilidad de las mujeres, niñas y adolescentes en contextos pluriculturales.

Teniendo en cuenta lo anteriormente señalado, se observa que la Corte Suprema ha señalado los límites o requisitos que deben concurrir al momento de aplicar lo dispuesto en el artículo 15 del Código Penal, ello porque conforme también se ha detallado, no se debe permitir el abuso y vulneración de los derechos de los menores o las menores, por el contrario, se debe siempre salvaguardar los intereses de los mismos, aun y cuando con posterioridad los actos hayan sido perdonados o compensados de una u otra forma.

Adicionalmente consideramos que uno de los criterios a tener en cuenta respecto a estos requisitos es no solamente mantener relaciones sexuales con una menor cuando ha iniciado su menstruación, sino que como criterio para atenuar o exculpar de responsabilidad penal, podría darse como referencia la pubertad del menor, y no únicamente en un caso que se encuentre condicionado a lo establecido en el artículo 15 del Código Penal, sino que podría ser tomado como directriz o fundamento en cualquier inicio de relación sexual, pero que también debe estar condicionado el hecho de mantener relaciones sexuales con una persona que ha alcanzado la pubertad, al hecho del porqué inicia las relaciones sexuales, si es por querer "alcanzar cierto grado de adultez" o si lo hace con la finalidad de querer procrear y formar una familia, y que además se mantenga en el tiempo.

Respecto a esto último la Corte Suprema en el Recurso de Nulidad N 761-2018/APURIMAC, caso en el que una menor mantuvo relaciones sexuales con una persona de veintiún años y que producto de dicha relación formaron una familia con dos hijos, tuvo a bien declarar la nulidad de la sentencia que lo condenó como autor del delito de violación sexual imponiéndole siete años de pena privativa de libertad, reformándola e imponiéndole cuatro años con carácter de suspendida condicionalmente.

El principal sustento de imponer una pena suspendida fue ponderar derechos referidos a la familia y a los integrantes de ella, sopesando por encima de una pena muy gravosa, el interés superior del niño e intereses de la familia, conforme a lo establecido por la normativa internacional (artículo 2, apartado 1 de la Convención sobre los Derechos del Niño). En este caso se hizo un 
análisis en virtud al principio de culpabilidad y la repercusión que pudiera tener la imposición de una pena efectiva, más aún si el condenado era el único sustento económico de dicha familia, lo que hubiera originado un problema mayor al haber quedado en abandono sus integrantes.

Evidentemente y como se ha sostenido anteriormente, la finalidad por la que debe aplicarse el principio de mínima intervención del derecho penal a la luz de los demás principios, se genera por cuanto el daño al bien jurídico protegido no resulta siendo tan gravoso, y por el contrario, la condena conlleva a la víctima y a las personas vinculadas a ella en cierto grado de indefensión para su supervivencia y manutención. Finalmente, no se debe dejar de lado que aun y cuando las principales características del principio de mínima intervención del derecho penal encuentren su sustento en la subsidiariedad y fragmentariedad, también forma parte de este principio el carácter proporcional (Monroy, s.f., p. 4) en la medida a que la medida a adoptar por la lesión a un bien jurídico protegido, debe estar en relación al mismo, por lo que si en aplicación de este principio se podrían vulnerar otros intereses del estado, se debe realizar una ponderación de bienes, para que así el resultado final no afecte de manera tan gravosa otros intereses que proteja el Estado, garantizando así la armonía dentro de una sociedad.

\section{Conclusiones}

El principio de mínima intervención del derecho penal se manifiesta como limitador del poder punitivo del Estado, al igual que el principio de legalidad y de lesividad, encontrando su aplicación desde dos fundamentos, el primero como mecanismo de última ratio en la que únicamente se puede recurrir al derecho penal cuando las demás instituciones no puedan solucionar la controversia o problema generado, y en segundo lugar, en la imposición de una pena, determinando para ello el grado de afectación al bien jurídico protegido y si con ella no se vulneran demás derechos.

Cabe la posibilidad imponer una pena privativa de libertad suspendida en su ejecución por la comisión del delito de violación sexual de menor de edad, siempre y cuando concurran como presupuestos el hecho de sostener el acto sexual con fines de convivencia familiar y que a su vez el sujeto activo mantenga una edad que evite abusos para con la menor.

En cuanto al error culturalmente condicionado, el hecho de mantener relaciones sexuales con una menor de edad no lo faculta para que este realice abusando de su condición, con violencia o que se busque una retribución o compensación para los familiares, por cuanto el bien jurídico protegido es la indemnidad sexual, generándose diversas afectaciones psicológicas en contra de la menor ante el abuso.

\section{Bibliografía}

BACIGALUPO ZAPATER, Enrique (2004). Derecho Penal Parte General, Lima, ARA Editores.

BRAMONT-ARIAS TORRES, Luis (2000). Manual de Derecho Penal Parte General, Lima, Editorial Santa Rosa.

CASTILLO ALVA, José Luis (2004). Principios del Derecho Penal, Parte General, Lima, Gaceta Jurídica.

CREUS MONTI, Carlos (2009). Derecho Penal Parte General, quinta edición, Buenos Aires, Editorial Astrea.

DE LA MATA AMAYA, José; SÁNCHEZ TOMÁS, José; ALCÁCER GUIRAO, Rafael; LASCURAIIN SÁNCHEZ, Juan (2007). Teoría del Delito, República Dominicana, Escuela Nacional de la Judicatura.

GARCía CAVERO, Percy (2010). Derecho Penal Parte General, segunda edición, Lima, Jurista Editores.

GARCÍA RIVAS, Nicolás (1996). El Poder Punitivo en el Estado Democrático, Castilla, Colección Estudios.

HUARCAYA RAMOS, Betty (2017). El principio de lesividad y mínima intervención en un Estado constitucional de derecho. En Actualidad Penal, enero de 2017, № 31, Instituto Pacífico, Lima.

JESCHECK, Hans-Heinrich (1981). Tratado de Derecho Penal, Parte General. Traducción por MIR PUIG, Santiago \& MUÑOZ CONDE, Francisco, Barcelona.

MONROY RODRÍGUEZ, Ángel. "Principio de Mínima Intervención ¿Retórica o Realidad?, [ubicado el 18.02.2019]. Obtenido en: file://D:/Users/MPFN/Documents/Downloads/4 827-Texto\%20del\%20art\%C3\%ADculo-10891-110-20160707.pdf, p.4.

MONTES FLORES, Efraín; PEÑA CABRERA FREYRE, Alonso; SÁNCHEZ MERCADO, Miguel (2006). El derecho penal contemporáneo: Libro homenaje al profesor Raúl Peña Cabrera, Tomo II, Lima, ARA Editores.

NÚÑEZ CHASQUERO, José Carlos (2016). El principio de mínima intervención penal en el marco de la excepción de improcedencia de acción. En Actualidad Penal, setiembre, № 27, Instituto Pacífico, Lima.

PEÑA CABRERA, Alonso Raúl (2015). "Los Delitos Sexuales. Análisis dogmático, jurisprudencial, 
procesal y criminológico", Segunda Edición, Lima, Ideas - Solución Editorial.

POLAINO NAVARRETE, Miguel (2008). Introducción al Derecho Penal, Lima, GRIJELY.

REÁTEGUI SÁNCHEZ, James (2009). Derecho Penal Parte General, Lima, Gaceta Jurídica.

REÁTEGUI SÁNCHEZ, James (2014). Manual de Derecho Penal Parte General, Lima, Instituto Pacífico.

SALINAS SICCHA, Ramiro. (2016). Los delitos contra la libertad e indemnidad sexual, Tercera Edición, Lima, Instituto Pacífico.

VELÁSQUEZ VELÁSQUEZ, Fernando. Anteproyecto de la parte general del Código Penal peruano de 2009 y los límites a la potestad punitiva del Estado, [ubicado el 18.02.2019]. Obtenido en: https://ficheros012.s3.amazonaws.com/06/19/1
m_1_3_380365854_in1_47_81.pdf?AWSAccess

Keyld=1V02DOW3KSR4KHZ90B82\&Expires $=1380$ 395733\&Signature $=$ S\%2F\%2FsP34jMcBoBidMnR aT1I3JeN8\%3D

VILLAVICENCIO TERREROS, Felipe (2006). Derecho Penal. Parte General, Lima, Grijley.

\section{Sentencias}

Tribunal Constitucional Exp. 016-2002 Al/TC

Tribunal Constitucional Exp. 033-2007-PI/TC

Recurso de Nulidad N 761-2018/Apurimac del 28.0518. Recurso de Nulidad N²239-2013-Callao del 15.07.14.

Recurso de Nulidad $N^{\circ}$ 1037-2004-Amazonas, del 01.07.04. 